in vivo $35: 805-813(2021)$

doi:10.21873/invivo.12321

\title{
Gene Expression Profile of Vascular Endothelial Growth Factors (VEGFs) and Platelet-derived Growth Factors (PDGFs) in the Normal Cornea
}

\author{
ANDREI RADU DAN COSNITA ${ }^{1}$, MARIUS RAICA ${ }^{2,3}$, MIHAI POENARU SAVA $^{1}$ and ANCA MARIA CIMPEAN ${ }^{2,3}$ \\ ${ }^{1}$ Department IX, Surgery I/Ophthalmology, \\ Victor Babes University of Medicine and Pharmacy, Timisoara, Romania; \\ ${ }^{2}$ Department of Microscopic Morphology/Histology, \\ Victor Babes University of Medicine and Pharmacy, Timisoara, Romania; \\ ${ }^{3}$ Angiogenesis Research Center, Victor Babes University of Medicine and Pharmacy, Timisoara, Romania
}

\begin{abstract}
Background/Aim: Angiogenic growth factors expression is not known in the normal cornea. The aim was to study corneal gene expression profile of VEGF and PDGF pathways influencing the avascular state of cornea. Materials and Methods: cDNA synthesis was performed from $m R N A$ extracted from five fresh pig corneas followed by $c D N A$ synthesis and analysis of VEGF and PDGF pathways by TaqMan Array gene expression profile. Results: Normal pig cornea lacks VEGFR2 and VEGFR3 gene expression. $M K 2$ and AKT1 genes were significantly overexpressed ( $p=0.000684, p=0.050995$, respectively). Six PDGF pathway genes were overexpressed: TIAM1 $(p=0.047)$, PIK3CA ( $p=0.00005), I K B K G$ ( $p=0.000006)$, PAK4 ( $p=0.034), R A C 1$ $(p=0.000006$ and PTGS2, $p=0.00375)$. PDGF A was upregulated, but not with a statistical significance $(p=0.79911)$, while PDGFR $\alpha$ was down-regulated and PDGFR $\beta$ was not expressed. Conclusion: Normal cornea avascularity is given by growth factor receptors down-regulation. Rapid corneal neovascularisation is induced by activation of the main angiogenic growth factors that induce angiogenic cascade and vessel recruitment.
\end{abstract}

This article is freely accessible online.

Correspondence to: Anca Maria Cimpean, MD, Ph.D., Full Professor of Histology, Pathologist, Department of Microscopic Morphology/Histology, Angiogenesis Research Center, "Victor Babeș" University of Medicine and Pharmacy, Piata Eftimie Murgu nr. 2, 300041, Timisoara, Timis, Romania. Tel: +40 720060955 , e-mail: acimpeanu@umft.ro, ancacimpean1972@yahoo.com

Key Words: Angiogenesis, TaqMan array, platelet derived growth factor, vascular endothelial growth factor.
Cornea is an avascular tissue in healthy individuals, but has the ability to become vascularized during several pathological conditions such as corneal inflammation, traumatic injuries, viral infections or following hypoxic conditions given sometimes by contact lens wear (1). Normal cornea avascularity represents one of the most important factors involved in corneal transparency and its normal functional state and thus, the ingrowth of blood vessels invading corneal tissue is followed by a continuous and sometimes irreversible damage of corneal epithelial and connective tissue structures together with a slow or abnormal healing (usually done by corneal fibrotic scars). An angiogenic cascade is activated in all previously mentioned pathologic conditions and corneal neoangiogenesis is initiated (2-4) by an imbalance between endogenous corneal antiangiogenic and angiogenic factors (3).

Few data are available on the genetic profile of angiogenic growth factors and their correspondent receptors in normal cornea. In 1997, van Setten described a VEGF like substance in the basal layer of normal human corneal epithelium and pointed out its overexpression due to a corneal traumatic injury. He stated that, VEGF presence inside cornea might be an important factor in the cascade leading to onset of corneal neovascularization (5). In 2006, the researchers at the Schepens Eye Research Institute pointed out for the first time that corneal transparency is guided at the molecular level by a large amount of non-vascular VEGF receptor 3 expressed in normal corneal epithelium (6).

All other data in the literature refer to the expression of VEGF family members in pathological conditions such as corneal inflammation or corneal mechanical lesions $(7,8)$. For this reason, studies of targeted therapies to counteract vascular effects of corneal inflammation have already been initiated $(9,10)$.

Also, few data are reported regarding the expression of PDGF and corresponding receptors in the normal cornea. 
Hoppenreis et al., described the expression of both PDGF receptors $\alpha$ and $\beta$ in a variety of corneal cells including epithelial cells, fibroblasts and endothelial cells (11). Recently, PDGF family members are intensely being studied in relationship to their expression in eye myofibroblasts, related to corneal avascular and vascular healing mechanism $(12,13)$.

Pig cornea represents in this moment more than an experimental tool used in eye research. It is already a promising alternative for corneal transplants in humans. Recently, Sharifi et al. (14) applied a GRAVY score (including primary amino acid structures, isoelectric point and grand average of hydropathy) to compare the similarity between human cornea and 14 other species. They reported that the pig cornea has the highest similarity score regarding the collagen types $(93.8 \%)$ and also protein content $(91.8 \%)$ with human cornea (14). Based on their findings, the final conclusion of the study was that porcine cornea has a higher relative suitability for corneal transplantation into humans compared to other studied species (14). Their conclusions seem to open a gate through the use of pig corneas as a main alternative for corneal transplantation.

The use of pig cornea xenotransplantation is not a novelty, dating back in 1838, when an unsuccessful pig to human cornea transplant had been performed (15). Since then, more than 100 pig to human corneal xenotransplantations have been performed in China, starting from 2010 till present but several controversies still persist regarding humoral and cellular response and microbiologic issues of pig to human corneal xenotransplantation $(16,17)$. Some of these controversies were gradually removed by using genetic engineering or by improving research in the field $(18,19)$.

Related to cornea pig use for xenotransplantation one issue is completely neglected at this moment: the characterisation of VEGF and PDGF pathways in its normal state.

Our preliminary observations (unpublished data) using normal pig cornea implanted on chick embryo chorioallantoic membrane (CAM) suggested that pig corneal tissue is able to induce a CAM vessel inhibition around the implant and moreover, no blood vessels acquisition by implanted cornea have been observed, remaining nonvascularized during the whole experimental study. This observation was the trigger initiating the present study which aims to characterize VEGF and PDGF gene expression profile pathways in normal pig cornea by using TaqMan gene expression assays. We would like to point out that we were not able to find in the literature an accurate gene expression profile of VEGF and PDGF pathways in normal pig cornea, most of the article describing their expression in pathologic conditions. Characterisation of normal corneal tissue regarding factors related to VEGF and PDGF pathways is necessary and may be useful for a better understanding of its avascular state.

\section{Materials and Methods}

Primary processing of the normal pig corneal tissue. Five pig corneas were harvested by an ophthalmologist from pigs sacrificed for commercial purposes. Half of the cornea from each specimen were used for RNA extraction and another half was introduced in saline solution $0.9 \%$ for about 30 min during its transport to chick embryo chorioallantoic membrane (CAM) experimental lab for CAM implantation procedure. The present study was approved by the decision of Ethics Committee of Victor Babes University of Medicine and Pharmacy Timisoara, Romania, no. 34/17.11.2017.

Chorioallantoic membrane assay preparation. Briefly, 5 fertilized eggs were incubated for $72 \mathrm{~h}$ at $37^{\circ} \mathrm{C}$ and $60 \%$ humidity. On day 3 of incubation, $2 \mathrm{ml}$ of albumen was removed from the eggs through a small hole performed into the eggshell on the opposite tip to air chamber containing tip. The eggs incubation continued and after 24 $\mathrm{h}$ a small window was performed on the eggshell to highlight vascularized chorioallantoic membrane (CAM). The corneal tissue implants were done on day 5 of incubation and the experiment continued till day 14 of incubation.

Corneal implants on CAM. Fresh corneal tissues were implanted on CAM surfaces after a preliminary scarification of the CAM on a free blood vessels area, usually in the angle delineated by two big blood vessels of the CAM, by using a stereomicroscopic guided implantation technique. The CAM corneal implants were observed for 9 days by evaluating their ability to acquire blood vessels, and also, by observing the arrangement of CAM blood vessels around the implants.

Histopathological evaluation of CAM implants. Nine days from corneal tissues implants on CAM the experiment was stopped by adding $10 \%$ buffered formalin in ovo and lasting for 2 hours to fix the tissues. The implants were harvested, and they continued to be fixed for 24 hours at room temperature followed by routine primary processing of the tissues and paraffin embedding. Three micrometers thick sections were performed from each specimen and stained with haematoxylin and eosin for microscopic evaluation of corneal tissue vascular status and normal structure.

RNA extraction and cDNA synthesis. Total RNA purification from corneal tissues was performed by magnetic particle-based technology following a standardized protocol for RNA extraction from fresh tissues, provided with Thermo Scientific ${ }^{\mathrm{TM}}$ KingFisher $^{\mathrm{TM}}$ Pure RNA Tissue Kit (code 98040196/98040496; Thermo Scientific, Waltham, MA, USA). We set RNA extraction by using $20 \mathrm{mg}$ corneal tissue which was mechanically disrupted in lysis buffer followed by loading of the material into King Fisher Duo Prime automated purification system (Thermo Fischer Scientific). Total RNA quantitation was checked with Qubit ${ }^{\mathrm{TM}}$ 3.0 Fluorometer (Thermo Fischer Scientific) using preliminary samples preparation by using Qubit ${ }^{\mathrm{TM}}$ RNA HS Assay Kit (code Q32852).

TaqMan assays. Our study was focused on the study of VEGF and PDGF pathways in corneal tissue. The pre-configured 96-well plates for TaqMan ${ }^{\circledR}$ Gene Expression Assays were used for both VEGF and PDGF pathways. Each plate contains pre-defined assays and endogenous controls, ready for accurate assessment of an entire gene signature in one simple experiment. 
The TaqMan ${ }^{\circledR}$ Array Human VEGF Pathway 96-well Plate contains 44 assays to VEGF Pathway associated genes and 4 assays to candidate endogenous control genes. TaqMan Array Human PDGF pathways plate includes 4 control genes and 92 genes

From the extracted RNA, the cDNA required for the TaqMan assays was performed by using High-Capacity RNA-to-cDNA ${ }^{\mathrm{TM}}$ Kit (Applied Biosystems, Waltham, MA, USA) following the protocol provided by the manufacturer.

TaqMan Array plates were prepared by loading on each well $20 \mu \mathrm{l}$ of cDNA sample with nuclease free water $(10 \mu \mathrm{l})$ and $10 \mu \mathrm{l}$ of Master Mix (2x).

Both TaqMan Array Human PDGF and VEGF cDNA-loaded plates were subjected to RT-PCR technique performed on 7500 Fast Dx Real-Time PCR Instrument (Applied Biosystem), following the protocol described in Figure 1.

Microscopic evaluation and statistical analysis. Daily evaluation of corneal tissues implants on CAM was performed by using Axio CAM Stereo Microscope (Zeiss, Oberkochen, Germany), and pictures from different stages of the experiment were obtained and processed with ZEN software (version 2, Zeiss, Oberkochen, Germany). Microscopic evaluation of the specimens was performed using an Axio Zoom 2 Observer Microscope (Zeiss). Haematoxylin and eosin stained slides were scanned by using Pannoramic Desk Digital Scanner (3D Histech, Budapest, Hungary), archived in the Case Center and viewed with Case Viewer, a software provided with scanning system and able to give an overview from the whole slide and capturing pictures from area of interest. TaqMan assays results were evaluated by using Data Assist V.3.01 system, assuming a statistically significant value of $p \leq 0.05$. Heat Map and volcano plots were generated from this analysis.

\section{Results}

The effects of normal pig cornea implants on chick embryo $C A M$. On day 5 of incubation, before corneal tissue implantation, the chick embryo CAM had a well-developed vasculature with a branched, interconnected, high density capillaries network covering all CAM area.

Corneal implants were highly adherent to CAM surface and they kept their viability in an avascular state during all 9 days of the experiment. Moreover, the implants gradually inhibited CAM vasculature as can been seen in Figure $2 a-c$. On the last experimental day, we observed a strong and complete inhibition of CAM vasculature (Figure $2 d$ and e). The corneal implants did not show any vessel acquisition. The avascular state of corneal implants on CAM was certified by their microscopic evaluation (Figure 2f).

The lack of vessels acquisition by the corneal implants suggested that other factors regarding VEGF and PDGF pathways may be involved in the maintenance of the avascular state. Thus, we consider it useful to evaluate the gene expression profile of VEGF and PDGF pathways in normal cornea.

Gene expression profile of VEGF pathway evaluated by TaqMan Array in normal pig cornea. Two VEGF pathway genes have been detected to be statistically significant overexpressed in normal pig cornea: MK2 gene

\begin{tabular}{|l|c|c|c|}
\hline \multicolumn{1}{|c|}{ Step } & Temperature & Time & Cycles \\
\hline UNG incubation & $50^{\circ} \mathrm{C}$ & 2 minutes & 1 \\
\hline Enzyme activation & $95^{\circ} \mathrm{C}$ & 20 seconds & 1 \\
\hline Denature & $95^{\circ} \mathrm{C}$ & 1 second & \multirow{2}{*}{40} \\
\cline { 1 - 3 } Anneal / Extend & $60^{\circ} \mathrm{C}$ & 20 seconds & \\
\hline
\end{tabular}

Figure 1. Step by step protocol for RT-PCR technique applied for TaqMan assays.

(MAPKAPK2, $p=0.000684)$ and AKT1 gene $(p=0.050995)$. Two other genes for VEGFA and VEGFC respectively were found to be overexpressed, but with no statistical significance. VEGFR2 and VEGFR3 were not found to be expressed in normal pig cornea (Figures $3 \mathrm{a}$ and $4 \mathrm{a}, \mathrm{b}$ ). This divergent gene expression profile of angiogenic and lymphangiogenic factors as VEGF $\mathrm{A}$ and $\mathrm{C}$ and their corresponding receptors (VEGFR2 and R3) may explain, partially, the lack of vessels acquisition by corneal implants.

PDGF pathway gene expression profile in normal pig cornea. The PDGF pathway was characterized by statistically significant overexpression of six genes: TIAM1 $(p=0.0477)$, PIK3CA $\quad(p=0.00005), \quad$ IKBKG $\quad(p=0.000006), \quad$ PAK4 $(p=0.034), \operatorname{RAC} 1(p=0.000006)$, PTGS2 $(p=0.00375)$, also the overexpressed but non-statistically significant gene coding for PDGFA $(p=0.799111)$. A decrease in the gene encoding PDGFR alpha and the lack of encoding PDGFR beta gene expression has been observed (Figures $3 b$ and $4 b$ ).

\section{Discussion}

Normal cornea has no blood vessels in its normal state. The corneal avascularity (for both blood and lymphatic vessels) is most likely dependent on a balance between proangiogenic and antiangiogenic factors previously described as being present in the corneal tissue.

Among several antiangiogenic factors of the corneal tissue, thrombospondin 1 and 2 (TSP1, TSP2) are currently considered the main factors responsible for the absence of blood vessels in the cornea (20). Other factors with antiangiogenic role were not explicitly reported for the normal cornea. In our study we identified two genes significantly overexpressed in the normal cornea: Akt1 (protein kinase B) and MK2 (MAPKAPK2), a gene of the activated mitogen protein kinase family. The two genes play a dual role in angiogenesis and in maintaining connective tissue homeostasis. Akt1 plays a dual (proangiogenic or antiangiogenic) role depending on its activation state duration: short-term activation causes a proangiogenic effect while chronic activation induces a strong antiangiogenic effect by stimulating the synthesis of TSP1 and TSP2 (21). It appears that in the normal cornea there is a chronic activation of Akt1 with increased synthesis of 

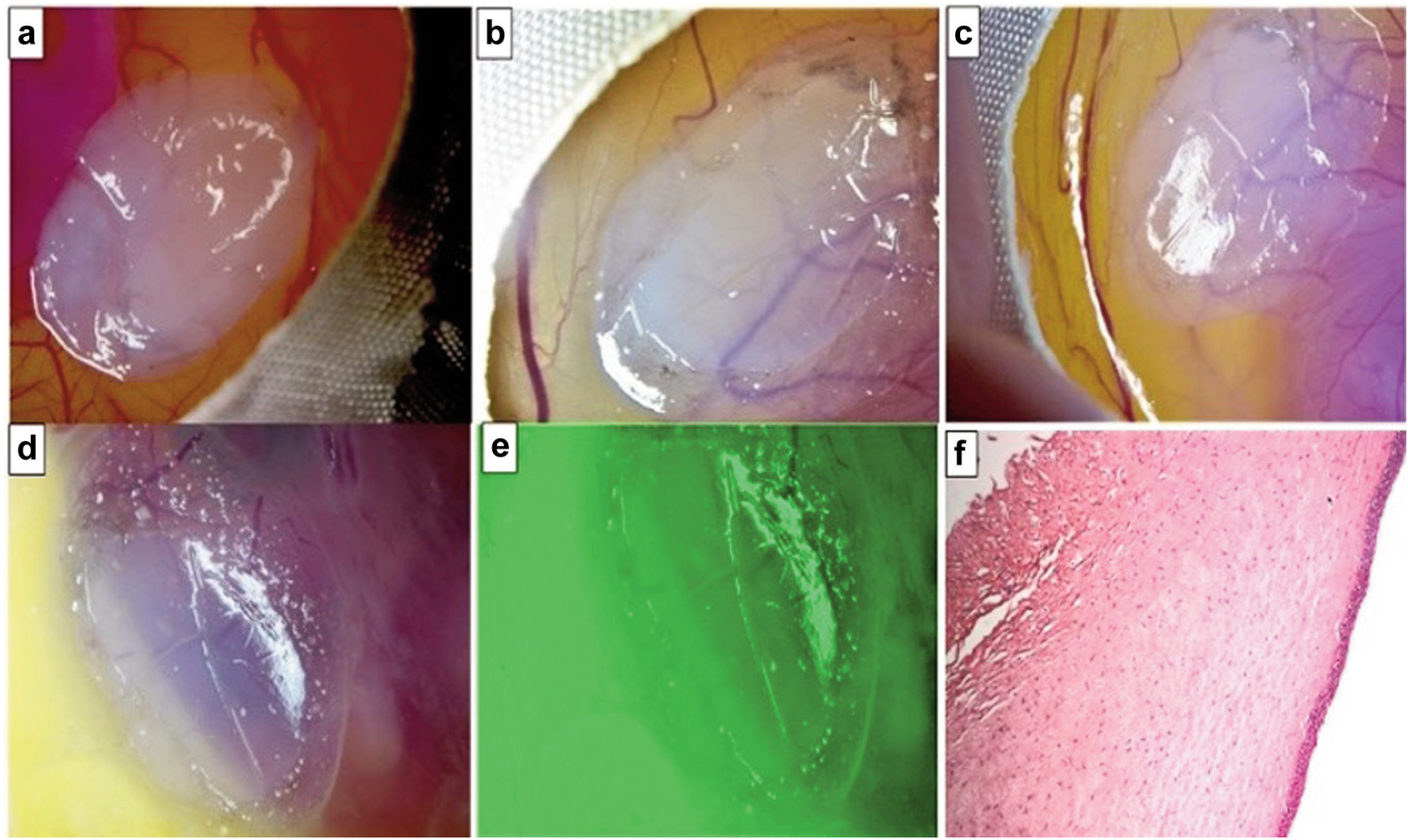

Figure 2. CAM vessels evaluation during 9 days of corneal implants on chick embryo CAM starting from day 1 of implantation (a) where the presence of blood vessels around the implant is observed. Note that the vascular network gradually decreases around the implants. The CAM vascular network is continuously decreasing, being more evident on day $3(b)$, day $7(c)$ and day $9(d, e)$ post-implantation. Microscopic evaluation of corneal tissue showed the lack of blood vessels acquisition, during experimental implantation, also and proved its avascular state (f).

TSP1 and TSP2 (in which the Akt1 gene plays an essential role), which induces corneal avascular status.

Several studies have been conducted on Akt1 activity in endothelial cells. It has been shown by Hellesoy and coworkers that Akt1 is dependent on the microenvironment where it carries out its activity so that it can inhibit the proliferation and migration of endothelial cells in addition to inhibiting the recruitment of endothelial cells (22). Based on our findings regarding Akt1, we consider that its overexpression represents one of the several antiangiogenic mechanisms that act to keep the normal cornea in an avascular state. Previously, Akt1 was studied in the normal cornea in relation to its role in activating corneal fibroblasts. Matching of Akt1 with PIK3CA (also overexpressed in our study for the PDGF pathway) has an antiapoptotic effect on corneal fibroblasts. Also, it has been reported that PI3-K/Akt/JNK/NF$\mathrm{KB}$ pathway stimulate the migration of corneal limbal epithelial stem cells $(23,24)$ during continuous physiologic renewal of corneal epithelium which take place without the involvement of blood vessels. Thus, Akt1 overexpression in normal cornea may be involved in avascular corneal repair usually observed in the central zone of the cornea (25).
Other antiangiogenic factors involved in the avascular state of the cornea are endostatin and neostatin (26). Endostatin is certified in the basal membranes of the cornea and in its extracellular matrix and it is considered to be an antiangiogenic factor but at this time without a well-defined scientific support (27). The present study reports for the first time Akt1 involvement in corneal avascularity being evaluated as part of the VEGF pathway.

The second overexpressed gene in our study was MK2 (MAPKAPK2), which is part of the MAPKs family with a wellknown involvement into the angiogenic cascade. This gene is involved together with Aktlgene in multiple cell processes regulating stress and inflammation response as well as regulating cell proliferation. In our study, the MK2 overexpression was higher than that of Akt1. None of the two genes has been so far reported as an antiangiogenic factor in the normal cornea. There were most studied in malignant conditions correlated with microvascular density. Overexpression of MK2 in the normal cornea seems to be a paradox as this as a precedent may also have an angiogenic role. Interaction between Akt1 and MK2 is certified and recognized as a direct mechanism, while interaction between MK2 and VEGF is 
a

Volcano plot (Study: VEGF CORNEA, 1 vs. 2, Fold change boundary: $2.0, p$-Value boundary: 0.05 )

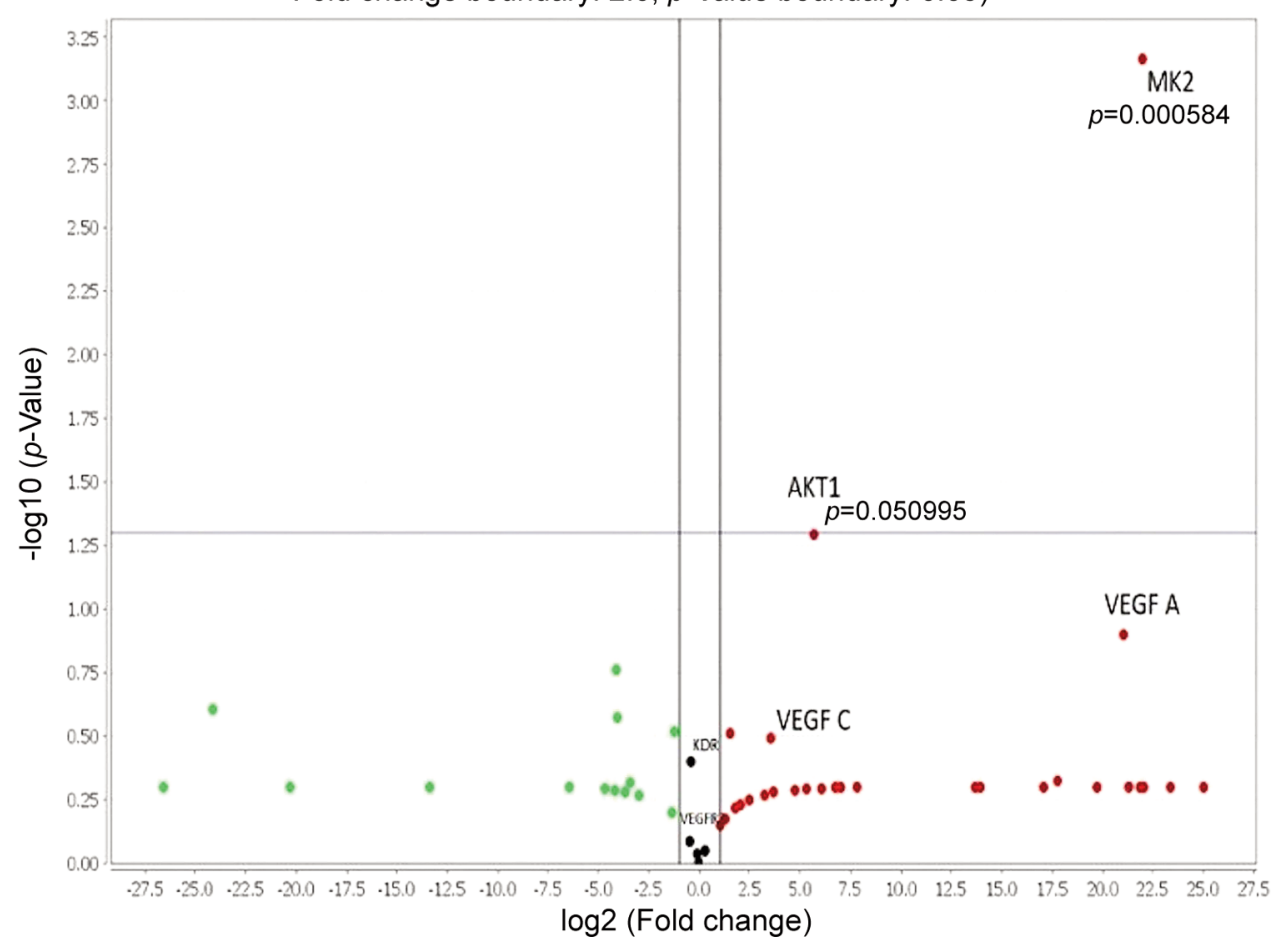

b

Volcano plot (Study: PDGF.CORNEE, 1 vs. 2 , Fold change boundary: 2.0, $p$-Value boundary: 0.05 )

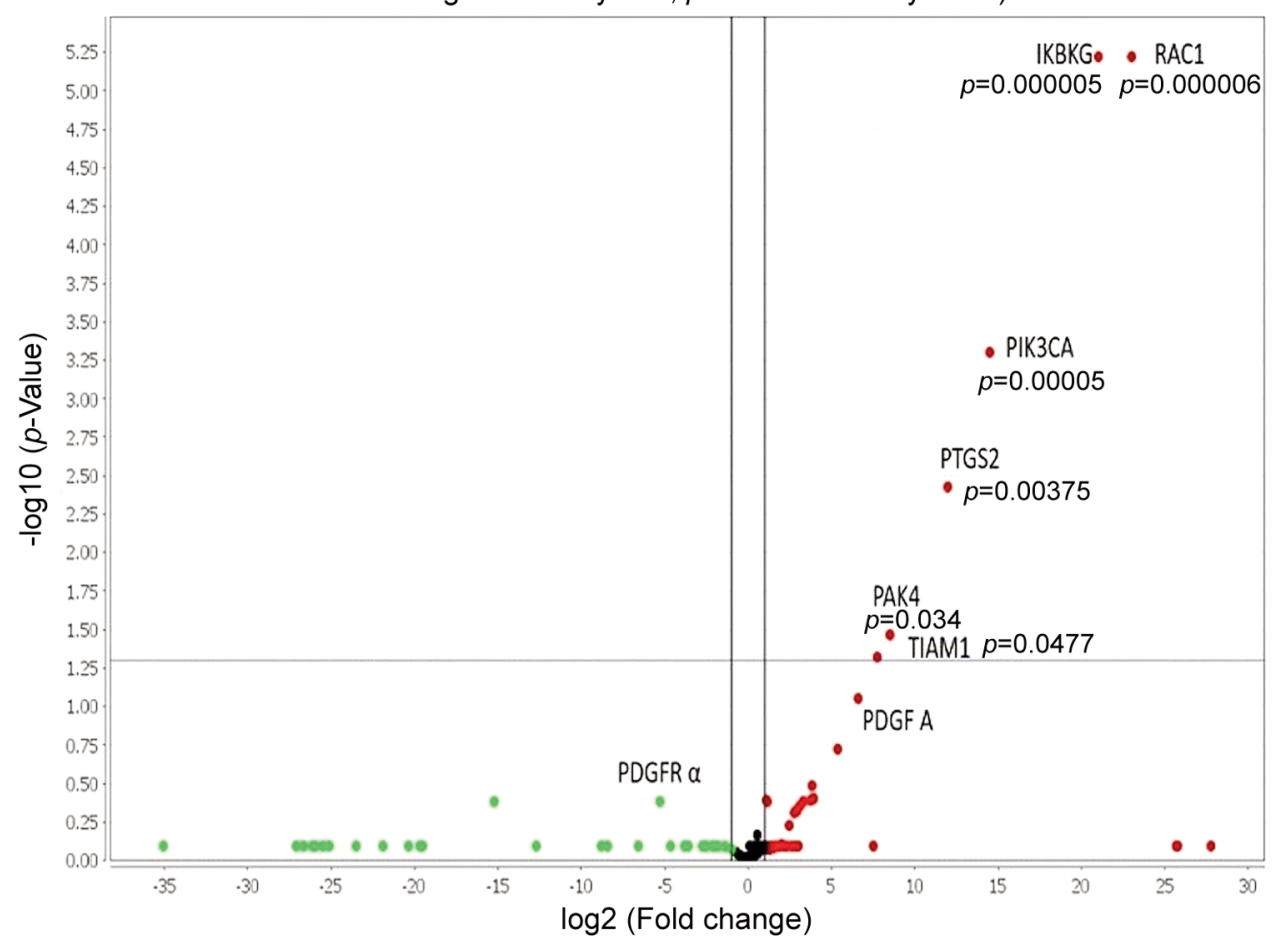

Figure 3. Volcano plot of VEGF pathway gene expression profile (a) and PDGF pathway gene expression profile (b) allowing data visualisation of normal pig cornea. Note that normal pig cornea showed VEGF A and VEGF C gene overexpression but lacks gene expression for their correspondent receptors KDR (VEGFR2) and VEGFR3 (a). Note the statistically significant overexpression for six genes (IKBKG, RAC1, PIK3CA, PTGS2, PAK4, TIAMI and one with non-statistical significance (PDGF A) while PDGFR gene was downregulated (b). 

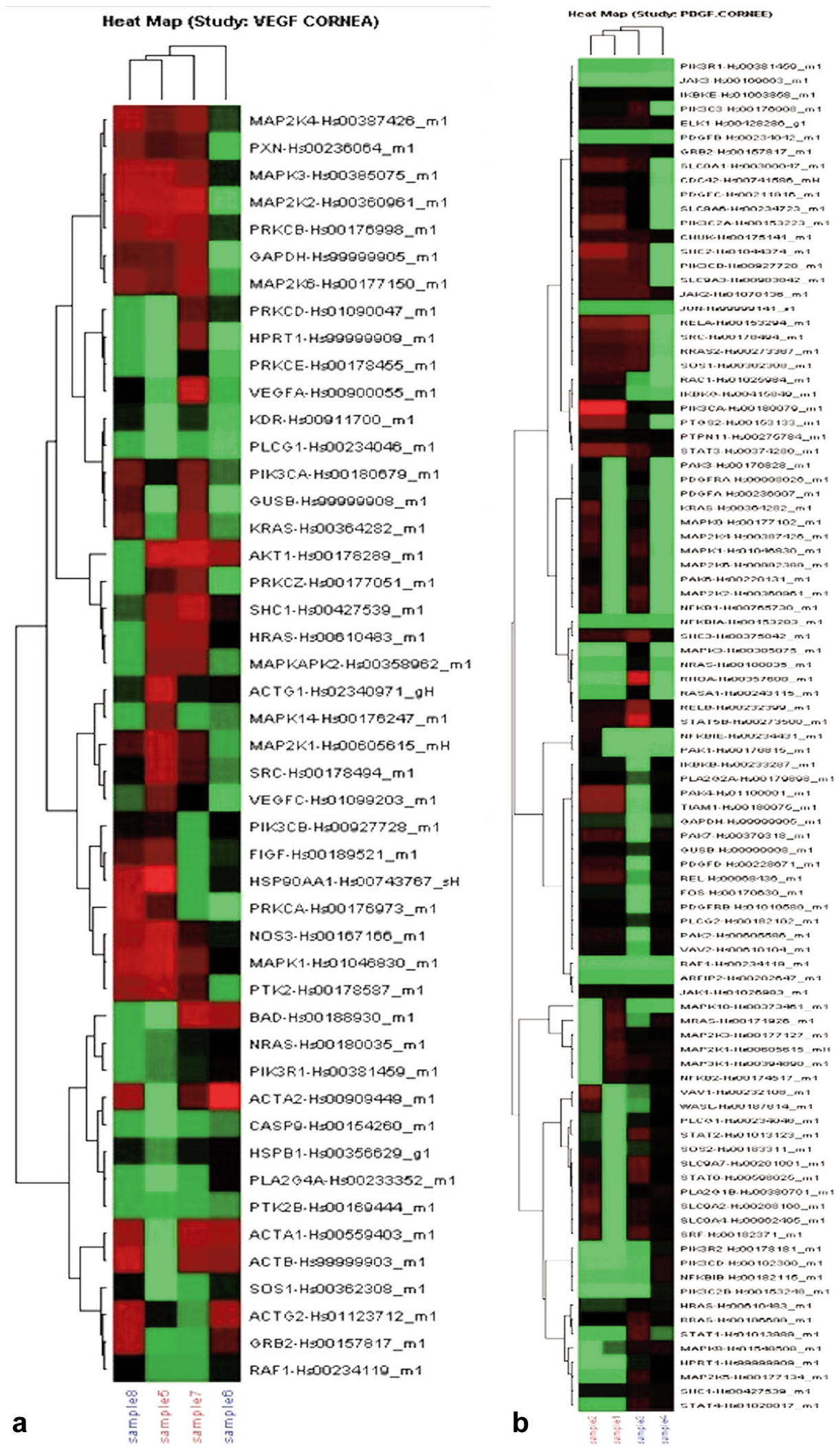

Figure 4. HeatMap correspondent to VEGF pathway (a) and PDGF pathway (b). Gene overexpression was highlighted in red, no expression in black and low (under) expression in green. 
mediated by a co-partner of MK2 gene, heat shock protein 27 (Hsp27) which is also stimulated by VEGF (28). This has been confirmed in our study by identifying the overexpression of both VEGF A and VEGF C along with MK2 overexpression. Most probably, VEGF-MK2 angiogenic effects may be counteracting in the normal cornea by lacking VEGFR2 and VEGFR3 gene expression the main key regulators of VEGF functions explaining by this way the lack of both blood and lymphatic vessels in the normal corneal tissue.

MK2 is involved in pulmonary fibrosis and is responsible for stimulating the synthesis and deposition of fibroblastderived collagen (29). The high amount of MK2 in normal cornea is given by the presence of collagen secreting fibroblasts but its function regarding endothelial cells migration and proliferation is blocked by the absence of correspondent receptors (26). Furthermore, it is well known that MK2 stimulation results in a significant increase in TGF beta, certified as having a protective role in maintaining the integrity of the normal cornea (30).

Our results support the VEGF $A$ and VEGF $C$ overexpression in normal pig cornea, but with no expression of VEGFR2 and VEGFR3. Several studies have evaluated levels of VEGF $\mathrm{A}$ and $\mathrm{C}$ and corresponding receptors in the cornea, this being the main mechanism reported to be responsible for initiating corneal angiogenesis (31). Van Setten reported the presence of VEGF A immunohistochemically detected in corneal epithelium and specified its heterogeneous expression, which can be increased after corneal epithelium damage (5).

Some studies explained the avascular state of the normal cornea by the existence of VEGFR1 soluble form able to catch VEGF A secreted by the intact corneal epithelium and thus preventing the angiogenesis initiation (32). In 2006, Cursiefen et al. described a non-vascular form of VEGFR3 in normal cornea (6) responsible for the maintaining of its avascular status. Other studies are in contradiction with the above data and report that VEGFR3 has a low expression or is not expressed in the normal cornea, but its level increases during corneal injuries. The same aspect was reported for VEGF C (33). Our results sustain the lack of VEGFR3 expression in normal cornea despite of VEGF C overexpression.

PDGF pathway characterisation is neglected in the normal cornea. Most data about PDGF overexpression is found in the injured cornea, PDGF being considered an important factor in regenerating the corneal epithelium and in corneal lesions healing. PDGF overexpression during corneal healing is considered a profibrotic factor that induces myofibroblasts development which are responsible for disordered extracellular matrix deposition to produce corneal scarring stromal fibrosis $(12,13)$. Our data demonstrated that in the normal cornea, PDGF $\mathrm{A}$ is overexpressed but not statistically significant, instead, the corresponding PDGFR $\alpha$ receptor is downregulated, while PDGFR $\beta$ is not expressed.
For the PDGF pathway, 6 genes have been overexpressed, most of them having a proangiogenic role in the PDGF intracellular signalling pathway. One of these belongs to the PI3K family and it is directly involved in the endothelial cell's proliferation, migration and angiogenesis cascade in close association with PDGFR $\beta$ (34). Despite the over-expression of PIK3CA in the normal cornea, the angiogenic process seems to be blocked by the absence of expression of the angiogenic co-factor PDGFR beta. The PDGFR $\alpha$ pathway appears to play a minor role in inducing angiogenesis in the normal cornea by the fact that PDGFR $\alpha$ is down-regulated and may not interact properly with PDGF A.

Inhibition of the PDGF A/PDGFR $\alpha$ pathway is one of the molecular targets in many cancers such as glioblastomas (35), colon carcinomas, hepatocellular carcinomas (36), all of which are closely correlated with the VEGF A pathway. This suggests that the normal cornea presents an indirect mechanism of inhibition of blood vessel formation by the absence or degradation of PDGFR $\alpha$ and $\beta$ expression despite the presence of PDGF A. It appears that the most important mechanism of inhibition of neovascularization related to the PDGF pathway is the lack of PDGFR $\beta$ expression. The interaction between RAC1 and another overexpressed gene in the cornea and PDGFR $\beta$ causes guided migration of endothelial cells into corneal connective tissue. This process is also mediated by the PIK3CA pathway that has the main effector PDGFR $\beta$ in the cornea (37). IKBKG has also been overexpressed in our study. Data related to its overexpression in the cornea are being reported related with healing of corneal lesions and with maintenance of the conjunctival balance by direct action on corneal fibroblasts (38-40). The PTGS2 gene recognized as COX2 encoding has also been overexpressed in our study. COX 2 is abundantly expressed in normal cornea as has been certified by Wang et al. by immunohistochemistry but COX2 gene overexpression has not been reported before. Our study is in concordance with Wang's findings and proved COX2 gene overexpression in normal corneal tissue (33). COX 2 is known to play a role in stimulating angiogenesis by forming new blood vessels through an interaction with VEGFR 2 and PDGFR $\beta$ (41). Despite COX 2 overexpression, the absence of VEGFR2 and PDGFR $\beta$ expression in the normal cornea can be considered the key mechanism involved in the corneal angiogenic privilege.

\section{Conclusion}

The present study characterizes for the first time the gene expression profile of VEGF and PDGF pathways in normal pig cornea.

The balance between proangiogenic and antiangiogenic factors in the normal cornea is based on a series of paradoxes either by overexpression of proangiogenic factors or the lack of expression of the receptors involved in the angiogenesis 
process. VEGF $\mathrm{A}$ and $\mathrm{C}$ are overexpressed in the normal cornea; instead, there are missing the mandatory correspondent receptors to achieve the effect of the two factors, respectively we noticed the absence of expression of VEGFR 2 and VEGFR3. Overexpression of COX2 in the absence of VEGFR 2 does not induce an angiogenic response in normal cornea. AKT1 gene which by overexpression determines the increased synthesis of antiangiogenic factors, respectively TSP1 and TSP2, as well as the inhibition of endothelial cell migration.

PDGFR alpha and beta are absent in the normal cornea. Based on our findings, the proangiogenic status exists in normal cornea, but is counteracted by the lack of the main effectors as VEGFR 2, PDGFR $\alpha$ and PDGFR $\beta$ not expressed in the normal cornea.

\section{Conflicts of Interest}

The Authors have no conflicts of interest

\section{Authors' Contributions}

ARDC designed the study, performed all experimental methods and wrote the paper; MPS performed surgical procedures to harvest cornea; MR and AMC supervised the experimental procedures, wrote some parts of Discussion section and prepared the final draft of the manuscript.

\section{Acknowledgements}

The Authors thank to Patricia Berzava and Ciprian Onica for their technical support and to Victor Babes University of Medicine and Pharmacy Timisoara Romania for the financial support. Present paper is supported by funds kindly provided by Doctoral School of Victor Babes University of Medicine and Pharmacy Timisoara, Romania.

\section{References}

1 Sharif $\mathrm{Z}$ and Sharif W: Corneal neovascularization: updates on pathophysiology, investigations \& management. Rom J Ophthalmol 63: 15-22, 2019. PMID: 31198893.

2 Ambati BK, Nozaki M, Singh N, Takeda A, Jani PD, Suthar T, Albuquerque RJ, Richter E, Sakurai E, Newcomb MT, Kleinman ME, Caldwell RB, Lin Q, Ogura Y, Orecchia A, Samuelson DA, Agnew DW, St Leger J, Green WR, Mahasreshti PJ, Curiel DT, Kwan D, Marsh H, Ikeda S, Leiper LJ, Collinson JM, Bogdanovich S, Khurana TS, Shibuya M, Baldwin ME, Ferrara N, Gerber HP, De Falco S, Witta J, Baffi JZ, Raisler BJ and Ambati J: Corneal avascularity is due to soluble VEGF receptor1. Nature 443: 993-997, 2006. PMID: 17051153. DOI: 10.1038/ nature 05249

3 Azar DT: Corneal angiogenic privilege: angiogenic and antiangiogenic factors in corneal avascularity, vasculogenesis, and wound healing (an American Ophthalmological Society thesis). Trans Am Ophthalmol Soc 104: 264-302, 2006. PMID: 17471348.

4 Ellenberg D, Azar DT, Hallak JA, Tobaigy F, Han KY, Jain S, Zhou $\mathrm{Z}$ and Chang JH: Novel aspects of corneal angiogenic and lymphangiogenic privilege. Prog Retin Eye Res 29: 208-248, 2010. PMID: 20100589. DOI: 10.1016/j.preteyeres.2010.01.002

5 van Setten GB: Vascular endothelial growth factor (VEGF) in normal human corneal epithelium: Detection and physiological importance. Acta Ophthalmol Scand 75: 649-652, 1997. PMID: 9527324. DOI: 10.1111/j.1600-0420.1997.tb00623.x

6 Cursiefen C, Chen L, Saint-Geniez M, Hamrah P, Jin Y, Rashid S, Pytowski B, Persaud K, Wu Y, Streilein JW and Dana R: Nonvascular VEGF receptor 3 expression by corneal epithelium maintains avascularity and vision. Proc Natl Acad Sci USA 103: 11405-11410, 2006. PMID: 16849433. DOI: 10.1073/pnas.050 6112103

7 Mirabelli P, Mukwaya A, Lennikov A, Xeroudaki M, Peebo B, Schaupper M and Lagali N: Genome-wide expression differences in anti-Vegf and dexamethasone treatment of inflammatory angiogenesis in the rat cornea. Sci Rep 7: 7616, 2017. PMID: 28811496. DOI: 10.1038/s41598-017-07129-4

8 Binder DR, Herring IP, Zimmerman KL, Pickett JP and Huckle WR: Expression of vascular endothelial growth factor receptor-1 and -2 in normal and diseased canine eyes. Vet Ophthalmol 15: 223-230, 2012. PMID: 22117605. DOI: 10.1111/j.1463-5224.2011.00973.x

9 Cakmak H, Gokmen E, Bozkurt G, Kocaturk T and Ergin K: Effects of sunitinib and bevacizumab on VEGF and miRNA levels on corneal neovascularization. Cutan Ocul Toxicol 37: 191-195, 2018. PMID: 28874077. DOI: 10.1080/15569527.2017.1375943

10 Irani YD, Scotney PD, Klebe S, Mortimer LA, Nash AD and Williams KA: An anti-VEGF-B antibody fragment induces regression of pre-existing blood vessels in the rat cornea. Invest Ophthalmol Vis Sci 58: 3404-3413, 2017. PMID: 28692735. DOI: 10.1167/iovs.16-21343

11 Hoppenreijs VP, Pels E, Vrensen GF, Felten PC and Treffers WF: Platelet-derived growth factor: receptor expression in corneas and effects on corneal cells. Invest Ophthalmol Vis Sci 34: 637-649, 1993. PMID: 8449682.

12 Wilson SE, Torricelli AAM and Marino GK: Corneal epithelial basement membrane: Structure, function and regeneration. Exp Eye Res 194: 108002, 2020. PMID: 32179076. DOI: 10.1016/ j.exer.2020.108002

13 Wilson SE: Corneal wound healing. Exp Eye Res 197: 108089, 2020. PMID: 32553485. DOI: 10.1016/j.exer.2020.108089

14 Rocher M, Robert PY and Desmoulière A: The myofibroblast, biological activities and roles in eye repair and fibrosis. A focus on healing mechanisms in avascular cornea. Eye (Lond) 34: 232240, 2020. PMID: 31767967. DOI: 10.1038/s41433-019-0684-8

15 Sharifi R, Yang Y, Adibnia Y, Dohlman CH, Chodosh J and Gonzalez-Andrades M: Finding an optimal corneal xenograft using comparative analysis of corneal matrix proteins across species. Sci Rep 9: 1876, 2019. PMID: 30755666. DOI: 10.1038/s41598-018-38342-4

16 Crawford AZ, Patel DV and McGhee CNJ: A brief history of corneal transplantation: From ancient to modern. Oman J Ophthalmol 6: S12-S17, 2017. PMID: 24391366. DOI: 10.4103/0974-620X.122289

17 Hara $\mathrm{H}$ and Cooper DK: Xenotransplantation--the future of corneal transplantation? Cornea 30: 371-378, 2010. PMID: 21099407. DOI: 10.1097/ICO.0b013e3181f237ef

18 Hara $\mathrm{H}$ and Cooper DK: The immunology of corneal xenotransplantation: a review of the literature. Xenotransplantation 17: 338-349, 2010. PMID: 20955291. DOI: 10.1111/j.13993089.2010.00608.x 
19 Isidan A, Liu S, Li P, Lashmet M, Smith LJ, Hara H, Cooper DKC and Ekser B: Decellularization methods for developing porcine corneal xenografts and future perspectives. Xenotransplantation 26: e12564, 2019. PMID: 31659811. DOI: 10.1111/xen.12564

20 Song YW and Pan ZQ: Reducing porcine corneal graft rejection, with an emphasis on porcine endogenous retrovirus transmission safety: a review. Int J Ophthalmol 12: 324-332, 2019. PMID: 30809491. DOI: 10.18240/ijo.2019.02.21

21 Cursiefen C, Masli S, Ng TF, Dana MR, Bornstein P, Lawler J and Streilein JW: Roles of thrombospondin-1 and -2 in regulating corneal and iris angiogenesis. Invest Ophthalmol Vis Sci 45: 11171124, 2004. PMID: 15037577. DOI: 10.1167/iovs.03-0940

22 Somanath PR, Razorenova OV, Chen J and Byzova TV: Akt1 in endothelial cell and angiogenesis. Cell Cycle 5: 512-518, 2006. PMID: 16552185. DOI: 10.4161/cc.5.5.2538

23 Cheng CY, Hsieh HL, Hsiao LD and Yang CM: PI3-K/Akt/JNK/NF$\mathrm{KB}$ is essential for MMP-9 expression and outgrowth in human limbal epithelial cells on intact amniotic membrane. Stem Cell Res 9: 9-23, 2012. PMID: 22459175. DOI: 10.1016/j.scr.2012.02.005

24 Bonzano C, Canciani B, Olivari S, Papadia M, Bagnis A, Cutolo CA, Bonzano E, Pagani P, Cancedda R and Traverso CE: CFSE: A new method for identifying human limbal stem cells and following their migration in human cornea. In Vivo 33: 18511855, 2019. PMID: 31662512. DOI: 10.21873/invivo.11678

25 Puri S, Sun M, Mutoji KN, Gesteira TF and Coulson-Thomas VJ: Epithelial cell migration and proliferation patterns during initial wound closure in normal mice and an experimental model of limbal stem cell deficiency. Invest Ophthalmol Vis Sci 61: 27, 2020. PMID: 32790859. DOI: 10.1167/iovs.61.10.27

26 Hellesoy M, Blois AL, Tiron CE, Mannelqvist M, Akslen LA and Lorens JB: Akt1 activity regulates vessel maturation ina tissue engineering model of angiogenesis. Tissue Eng Part A 20: 25902603, 2014. PMID: 24957363. DOI: 10.1089/ten.TEA.2013.0399

27 Abdelfattah NS, Amgad M, Zayed AA, Hussein H and Abd ElBaky N: Molecular underpinnings of corneal angiogenesis: advances over the past decade. Int J Ophthalmol 9: 768-779, 2016. PMID: 27275438. DOI: 10.18240/ijo.2016.05.24

28 Michellaci YM: Collagens and proteoglycans of the corneal extracellular matrix. Braz J Med Biol Res 36: 1037-1046, 2003. PMID: 12886457. DOI: 10.1590/s0100-879x2003000800009

29 Evans IM, Britton G and Zachary IC: Vascular endothelial growth factor induces heat shock protein (HSP) 27 serine 82 phosphorylation and endothelial tubulogenesis via protein kinase D and independent of p38 kinase. Cell Signal 20: 1375-1384, 2008. PMID: 18440775. DOI: 10.1016/j.cellsig.2008.03.002

30 Liang J, Liu N, Liu X, Mena JM, Xie T, Geng Y, Huan C, Zhang Y, Taghavifar F, Huang G, Kurkciyan A, Barron V, Jiang D and Noble PW: Mitogen-activated protein kinase-activated protein kinase 2 inhibition attenuates fibroblast invasion and severe lung fibrosis. Am J Respir Cell Mol Biol 60: 41-48, 2019. PMID: 30130411. DOI: $10.1165 / \mathrm{rcmb} .2018-00330 \mathrm{OC}$

31 Tandon A, Tovey JC, Sharma A, Gupta R and Mohan RR: Role of transforming growth factor Beta in corneal function, biology and pathology. Curr Mol Med 10: 565-578, 2010. PMID: 20642439. DOI: $10.2174 / 1566524011009060565$

32 Nakano Y, Uchiyama M, Arima T, Nagasaka S, Igarashi T, Shimizu A and Takahashi H: PPAR $\alpha$ agonist suppresses inflammation after corneal alkali burn by suppressing proinflammatory cytokines, MCP-1, and nuclear translocation of NF-kB. Molecules 24: 114, 2018. PMID: 30597991. DOI: 10.3390/molecules24010114
33 Ambati BK, Nozaki M, Singh N, Takeda A, Jani PD, Suthar T, Albuquerque RJ, Richter E, Sakurai E, Newcomb MT, Kleinman ME, Caldwell RB, Lin Q, Ogura Y, Orecchia A, Samuelson DA, Agnew DW, St Leger J, Green WR, Mahasreshti PJ, Curiel DT, Kwan D, Marsh H, Ikeda S, Leiper LJ, Collinson JM, Bogdanovich S, Khurana TS, Shibuya M, Baldwin ME, Ferrara N, Gerber HP, De Falco S, Witta J, Baffi JZ, Raisler BJ and Ambati $\mathrm{J}$ : Corneal avascularity is due to soluble VEGF receptor-1. Nature 443: 993-997, 2006. PMID: 17051153. DOI: 10.1038/nature05249

34 Mimura T, Amano S, Usui T, Kaji Y, Oshika T and Ishii Y: Expression of vascular endothelial growth factor $\mathrm{C}$ and vascular endothelial growth factor receptor 3 in corneal lymphangiogenesis. Exp Eye Res 72: 71-78, 2001. PMID: 11133184. DOI: 10.1006/exer.2000.0925

35 Wang H, Yin Y, Li W, Zhao X, Yu Y, Zhu J, Qin Z, Wang Q, Wang K, Lu W, Liu J and Huang L: Over-expression of PDGFR$\beta$ promotes PDGF-induced proliferation, migration, and angiogenesis of EPCs through PI3K/Akt signaling pathway. PLoS One 7: e30503, 2012. PMID: 22355314. DOI: 10.1371/journal. pone.0030503

36 Cenciarelli C, Marei HE, Felsani A, Casalbore P, Sica G, Puglisi MA, Cameron AJ, Olivi A and Mangiola A: PDGFR $\alpha$ depletion attenuates glioblastoma stem cells features by modulation of STAT3, RB1 and multiple oncogenic signals. Oncotarget 7: 5304753063, 2016. PMID: 27344175. DOI: 10.18632/oncotarget.10132

37 Zhang JB, Sun H, Jia WD, Zhuang PY, Qian YB, Zhu XD, Kong LQ, Wang L, Wu WZ and Tang ZY: Up-regulation of plateletderived growth factor-A is responsible for the failure of reinitiated interferon alpha treatment in hepatocellular carcinoma. BMC Cancer 12: 439, 2012. PMID: 23025904. DOI: 10.1186/1471-2407-12-439

38 Anand-Apte B, Zetter BR, Viswanathan A, Qiu RG, Chen J, Ruggieri R and Symons M: Platelet-derived growth factor and fibronectin-stimulated migration are differentially regulated by the Rac and extracellular signal-regulated kinase pathways. J Biol Chem 272: 30688-30692, 1997. PMID: 9388204. DOI: $10.1074 / j b c .272 .49 .30688$

39 Chen L, Mongan M, Meng Q, Wang Q, Kao W and Xia Y: Corneal wound healing requires IKB kinase $\beta$ signaling in keratocytes. PLoS One 11: e0151869, 2016. PMID: 26987064. DOI: 10.1371/journal.pone.0151869

40 Chen L, Meng Q, Kao W and Xia Y: IkB kinase $\beta$ regulates epithelium migration during corneal wound healing. PLoS One 6: e16132, 2011. PMID: 21264230. DOI: 10.1371/journal.pone. 0016132

41 Garonna E, Botham KM, Birdsey GM, Randi AM, Gonzalez-Perez RR and Wheeler-Jones CP: Vascular endothelial growth factor receptor-2 couples cyclo-oxygenase- 2 with pro-angiogenic actions of leptin on human endothelial cells. PLoS One 6(4): e18823, 2011. PMID: 21533119. DOI: 10.1371/journal.pone.0018823

Received November 15, 2020

Revised November 26, 2020

Accepted December 3, 2020 